AIAA 2002-1357

\title{
PIEZOCERAMIC HOLLOW FIBER ACTIVE COMPOSITES
}

\author{
Bryan J. Cannon, Diann Brei \\ Department of Mechanical Engineering and Applied Mechanics, \\ The University of Michigan, Ann Arbor, MI 48109
}

\begin{abstract}
While active fiber composites (AFC) based upon solid cross-section piezoelectric fibers are very useful for anisotropic activation of composites, they require high voltages and are constrained to non-conductive matrix materials. AFC's based upon hollow cross-section piezoelectric fibers have shown promise to lower operating voltages and broaden the choice of possible matrix materials. This paper presents an investigation of the key design parameters for hollow piezoelectric fibers (matrix/fiber Young's moduli, aspect ratio of the individual fibers, and the overall active composite volume fraction) and their effect on the performance, manufacturing and reliability of active fiber composites. Because the ultimate objective in utilizing active composites centers on their ability to deform, an analysis was conducted on existing fiber and lamina strain/electric field models to identify optimal parameter values and determine limitations via an embedment stress model. Fabrication of the fibers has a clear impact on these factors. To assess this, standard machinery inspection criteria was used to evaluate fibers, manufactured through microfabrication by coextrusion (MFCX), with respect to their geometric (cross-sectional ovality, eccentricity, straightness) and material (density, porosity, piezoelectric properties, Young's modulus) properties. These studies indicated that there are circumstances under which low aspect ratio (thin walled) fibers will be optimal, but clearly, reliability issues will arise. Unfortunately, little data exists on reliability of either hollow or solid piezoelectric fibers. To identify the primary failure mechanism, ultimate strength, strain-to-failure and interfacial shear strength were examined using three types of experimental tests: 1) tensile strain-to-failure, 2) single fiber fragmentation, and 3) single fiber indentation. From this work, it is clear there will always be design trade-offs present and it is important to consider performance, fabrication, and reliability
\end{abstract}

Copyright (C) 2002 The American Institute of Aeronautics and Astronautics Inc. All rights reserved. issues simultaneously in the design of hollow piezoelectric fiber active composites.

Keywords: Active composites, piezoelectric, piezoelectric fibers, hollow fiber, smart structures, active fiber composites, PZT.

\section{INTRODUCTION}

Active Fiber Composites (AFC), ones in which smart materials are embedded directly into the composite matrix, have received a great deal of attention ${ }^{1-5}$ because they possess desirable characteristics for a wide range of smart structure applications such as vibration, shape, and flow control. ${ }^{6-11}$ One major advantage to AFC's is the ability to create anisotropic laminate layers, making them particularly useful in applications requiring off-axis or twisting motions. ${ }^{1,2}$ In addition, embedded fibers are damage tolerant and do not negatively affect the composite's interface with the environment. A common form of AFC that can generate high levels of strain (as high as 1700 microstrain) is based on embedded solid piezoelectric fibers activated by an external interdigitated electrode pattern. $^{2}$ This type of AFC has been employed in a twist configuration for control of a rotorcraft blade, where twist angles of several degrees have been achieved. ${ }^{10}$ The major drawback to this approach is the requirement of the electric field to pass through the composite matrix. Due to the placement of the electrode on the matrix surface, electric field losses are significant requiring high voltages (on the order of 1 $\mathrm{kV}$ ) for actuation. ${ }^{12}$ Furthermore, this approach limits the matrix to electrically nonconductive materials, which is particularly a problem in large structure and air vehicle applications where metals and carbon fiber composites are almost exclusively utilized in construction.

An alternative approach to solid fiber AFC's is based upon hollow piezoelectric fibers (Figure 1). These fibers, individually electroded on both the inside and outside surfaces, are activated by an electric field 


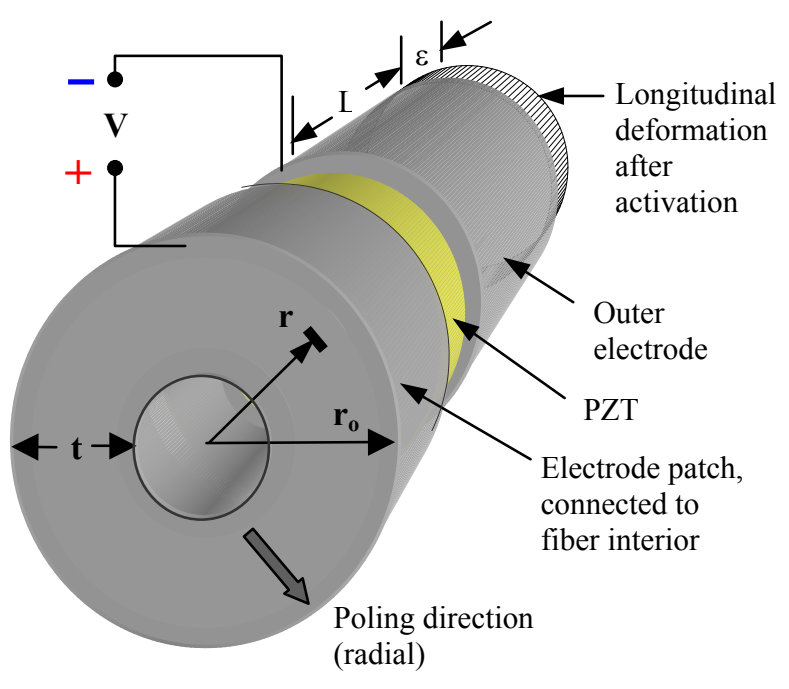

Aspect ratio, $\alpha=\mathbf{t} / \mathbf{r}_{\mathbf{o}}$

Figure 1. Hollow Fiber Design. The basic fiber design consists of a hollow cylinder of active material, electroded on both the inside and outside surfaces. For piezoelectric materials (PZT), the poling direction is radial; therefore the $d_{31}$ response of the fiber is used to create longitudinal motion.

applied directly across the walls of the fiber, generating longitudinal strain due to the piezoelectric $\mathrm{d}_{31}$ mode. Even though the longitudinal strain is decreased by approximately half by using $d_{31}$ versus the $d_{33}$ mode used in solid fiber AFCs, the required voltage can be decreased by a factor of ten or more since the electric field is applied only across the wall of the fiber instead of through the matrix, thereby eliminating field losses. An additional benefit to the hollow topology is the isolation of the inner electrode from the matrix, enabling the fiber to be embedded in electrically conductive matrices. ${ }^{3-5}$

Several processes, based on molding or extrusion techniques, are available for fabricating piezoelectric fibers - each with their own pros and cons. Molding techniques ${ }^{13-15}$ are capable of producing highly detailed cross-sections with wall thickness on the order of a grain size, although the fiber length is limited to $10 \mathrm{~mm}$ or less. Traditional extrusion or drawing methods ${ }^{16,17}$ can produce extremely long fibers (thousands of feet ${ }^{17,18}$ ), but are difficult and expensive to apply to hollow fiber fabrication. Microfabrication by Coextrusion (MFCX) is capable of inexpensively producing long ceramic forms $(>100 \mathrm{~mm}$ long) with complex cross-sections having small feature sizes (as small as a grain size); however, this method is still at the research stage and further characterization is required. ${ }^{19}$
While the feasibility of producing piezoelectric hollow fibers has been established ${ }^{3,18,20}$, there has been limited research in modeling and characterization of this new type of AFC. Most of the modeling efforts for hollow piezoelectric fibers has focused on the radial strain of short fibers used in hydrophone applications. ${ }^{4,5}$ Unfortunately, this research doesn't extend to longitudinal strain in long fibers. However, Maclean and Jacobsen ${ }^{3}$ have numerically modeled the nonlinear electric field behavior across the fiber walls. The authors have built on Maclean and Jacobsen's earlier work to derive basic analytical models capturing the strain behavior as a function of the nonlinear applied field in individual fibers and lamina. ${ }^{20}$

The research that has been conducted to date on hollow fiber composites has successfully demonstrated the basic feasibility of the concept. However, for engineers to use hollow fibers effectively in active composite design, they must be aware of the key design issues impacting performance, fabrication, and reliability of these fibers. For example, while basic performance models do exist for these hollow fibers, the relationship between the primary design parameters has not been fully studied. These parameters represent the range of choices available to the engineer when designing a composite, and include the fiber and matrix Young's moduli, aspect ratio of the individual fibers, and the overall active composite volume fraction.

All of these parameters are governed by the quality of the fabrication technique. For instance, traditional extrusion and drawing methods often suffer from poor ovality or eccentricity (out-of-roundness) due to handling of hollow green fibers during the fabrication process, which can ultimately result in electric field stress concentrations in the fiber wall. The MFCX process alleviates many of these issues by including a solid carbon black core in the green fiber; however, as with any ceramic processing technique the high temperatures experienced during the sintering phase have a tendency to shrink and warp the fibers. This warping can clearly affect the fiber layup and the achievable volume fraction, affecting the overall composite design. Thus, it is important to know exactly how the individual design parameters, particularly aspect ratio, influence the quality of the manufactured fiber.

Finally, very little research has been conducted on the reliability of active fiber composites, whether hollow or solid. It is known that long-fiber active composites are susceptible to reliability problems such as fiber pullout and breakage in much the same way as conventional (inactive) fibrous composites. ${ }^{7}$ Hollow fibers introduce another level of complexity due to the potentially 
fragile nature of the fiber walls. Therefore, it is critical when designing a hollow fiber active composite to know the primary failure mechanism and have a sense of the strain-to-failure and ultimate strength of the individual fibers in addition to the entire composite. This paper presents an in-depth study addressing these performance, fabrication and reliability issues for hollow piezoelectric fibers with concentration on the design tradeoffs presented by the primary design parameters: fiber aspect ratio, matrix/fiber modulus ratio, and composite volume fraction.

\section{HOLLOW FIBER COMPOSITE PERFORMANCE STUDY}

To gain insight into the sensitivity of the AFC performance to the primary design parameters (aspect ratio, fiber/matrix material, and volume fraction), individual fiber and AFC lamina models derived in previous work ${ }^{20}$ were analyzed with respect to each of the design parameters. For continuity, a brief summary of the fiber and lamina analytical models is presented before the analysis. For a more detailed derivation the reader is referred to previous literature. ${ }^{20,21}$

\section{Hollow Fiber Performance Modeling Summary}

Simple analytical models to predict the strain in AFC lamina were built up from the fiber level by establishing effective piezoelectric constant, $\mathrm{d}_{31 \text {,eff, for }}$ both the individual fiber and a lamina ply. This enables classical laminate composite methods to be applied when incorporating multiple hollow fiber laminas into complex composite architectures. At both the individual fiber and lamina level, these performance models were validated through experimentation and finite element models with correlation within $6.5 \%{ }^{20}$

Individual Fiber Model. In smart structures, it is common and convenient to model the electric field applied across a curved piezoelectric structure by the thin-wall approximation - the applied voltage divided by the wall thickness $\left(E_{t w}=V / t\right)$. However, in general the electric field through the thickness of a curved structure is not constant, with the approximation breaking down quickly as the thickness increases. Therefore, it is critical in the individual fiber model to account for the nonlinear electric field effects. From Gauss' Law, the expression for the electric field, $E$, at a distance, $r$, from the geometric center of a hollow circular fiber is ${ }^{22}$ :

$$
E(r)=\frac{-V}{r \ln (1-\alpha)},
$$

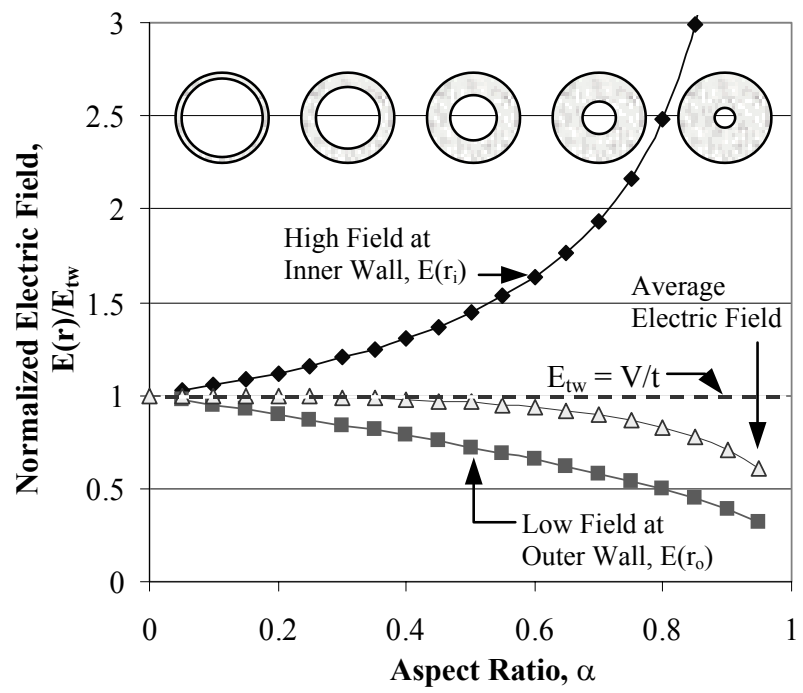

Figure 2. Electric Field vs. Aspect Ratio. As the aspect ratio of a hollow fiber increases, the difference between the maximum and minimum electric fields increases. The highest field occurs at the inside wall; the lowest field is located at the outside wall.

where $\alpha$ is the fiber aspect ratio, $t / r_{o}$, and $V$ is the voltage applied across the fiber wall. The field is maximum at the inner diameter (Figure 2) and decreases with increasing radius to a minimum at the outer diameter. The variation between maximum and minimum field increases with the fiber aspect ratio, $\alpha$. A significant variation in field can lead to severe problems. To produce an adequate poling field at the outer edge of a high aspect ratio fiber (thick wall), the electric field at the inner edge of the fiber must be so large that the induced stress may damage the fiber. Likewise, when activating a hollow fiber it is not possible to achieve the maximum working electric field at the outer edge because this voltage would overdrive the inside of the fiber resulting in de-poling. Thus, it is clear that the choice of aspect ratio has a significant effect on voltage levels needed for poling and fiber activation, with low aspect ratios being a preferred choice.

By integrating the internal piezoelectric forcing created by the local electric field (Equation 1) over the crosssection of the fiber, the longitudinal free strain, $\varepsilon$, is

$$
\varepsilon=\left(\frac{-d_{31}}{\ln (1-\alpha)(1 / \alpha-0.5)}\right) E_{t w}=d_{31, e f f}{ }^{F} E_{t w} .
$$

The effective $d_{31}$ of the fiber, $d_{31, e f f}$, (in parentheses) incorporates the nonlinear electric field effects, thus enabling the thin wall electric field approximation, $E_{t w}$, 


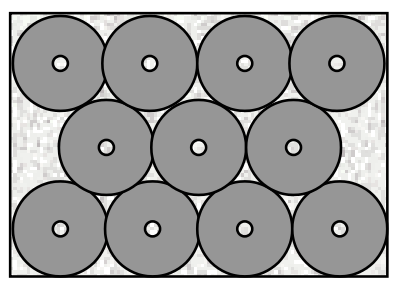

High Fiber Density

High Volume Fraction

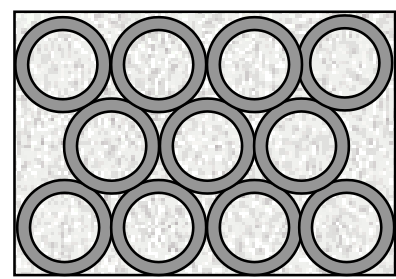

High Fiber Density Low Volume Fraction

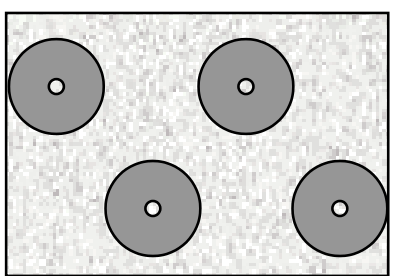

Low Fiber Density Low Volume Fraction

Figure 3. Volume Fraction vs. Fiber Density. The volume fraction refers to the overall volume of the composite taken up by fiber material. The fiber density refers to the number of fibers in a given volume divided by the maximum number of fibers that can be embedded into the same volume.

to be used to simplify the lamina composite models. Note that the effective fiber $\mathrm{d}_{31}$ is only a function of the aspect ratio of the fiber and the piezoelectric material $d_{31}$. The effective fiber $d_{31}$ increases with decreasing aspect ratio; therefore, as would be expected, fibers with low aspect ratio (thin wall) produce the highest strain for a given applied electric field.

Lamina Model. A classical composite theory, the concentric cylinders model ${ }^{23}$, was used to derive the expression for the equivalent lamina longitudinal Young's modulus, $Y_{\text {lam }}=Y_{f} v_{f}+Y_{m}\left(1-v_{f}\right)$, where $Y_{f}$ and $Y_{m}$ refer to the Young's modulus of the fiber and matrix, and $v_{f}$ is the fiber volume fraction (percentage of active material). In this model, it is assumed that each fiber is back-filled with matrix material in the determination of volume fraction. Dividing the equivalent Young's modulus by the modulus of the fiber yields, in dimensionless form,

$$
Y_{\text {lam }}{ }^{N}=\frac{Y_{\text {lam }}}{Y_{f}}=v_{f}+\frac{Y_{m}}{Y_{f}}\left(1-v_{f}\right),
$$

Recognizing that the piezoelectric strain in the fiber direction is analogous to thermal strains in a conventional composite, the strain of a hollow fiber lamina can be expressed as a product of the effective lamina $d_{31}, d_{31, \text { eff }}^{L}$ (given in the parentheses) and the thin wall approximation of the applied field $E_{t w}$,

$$
\begin{aligned}
\varepsilon_{\text {lamina }} & =\frac{1}{Y_{\text {lam }}}\left(\frac{-d_{31}}{\ln (1-\alpha)(1 / \alpha-0.5)}\right) E_{t w} \\
& =\left(\frac{-d_{31, e f f}}{Y_{\text {lam }}}\right) E_{t w}=d_{31, e f f}{ }_{t}^{L} E_{t w} .
\end{aligned}
$$

4

American Institute of Aeronautics and Astronautics
With the use of these effective piezoelectric parameters, models for any AFC layup architecture can be derived utilizing traditional laminate composite theory methods built upon this single lamina model. ${ }^{23}$

\section{Effective Lamina d ${ }_{31}$ Model Analysis}

From the above models, the primary design parameters are: aspect ratio, Young's modulus ratio $\left(Y_{m} / Y_{f}\right)$ and fiber volume fraction. These models can also be written in terms of fiber density, $\Delta_{f}$, instead of fiber volume. It is important to draw a distinction between volume fraction and fiber density. The volume fraction, $v_{f}$, used in the model derivation, is the percentage of the composite taken up by fiber material irrespective of how that material is arranged in the matrix. Fiber density, on the other hand, refers to the number of fibers in a given volume divided by the maximum number of fibers that can be embedded into the same volume. This is dependent only on the geometric arrangement of the fibers, not how much piezoelectric material is present. For solid fiber composites, volume fraction and fiber density are essentially interchangeable because the percentage of fibers uniquely determines the percentage of fiber material. For hollow fibers, however, the volume fraction is also determined by the aspect ratio of the fibers - two composites with an equal number of fibers (thus, equal fiber density) can have very different values of volume fraction depending on aspect ratio, as shown in Figure 3. Fiber density and volume fraction are related by the relationship,

$$
v_{f}=\left(\frac{\pi}{2 \sqrt{3}} \Delta_{f}\right)(2-\alpha) \alpha .
$$

Insight into the fiber strain behavior can be gained by studying the effective lamina $d_{31}$ assuming the applied electric field is constant. Figure 4 shows the effective lamina $d_{31}$, normalized with respect to the $d_{31}$ of the 


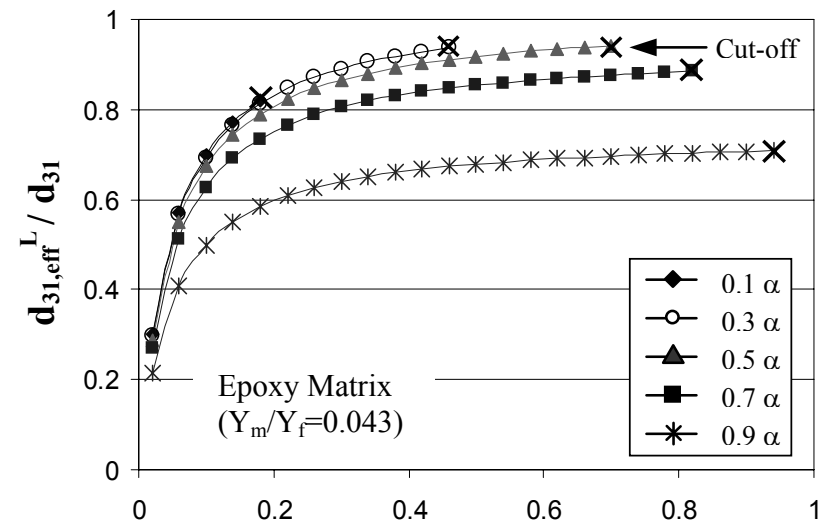

a) Fiber Volume Fraction, $v_{f}$

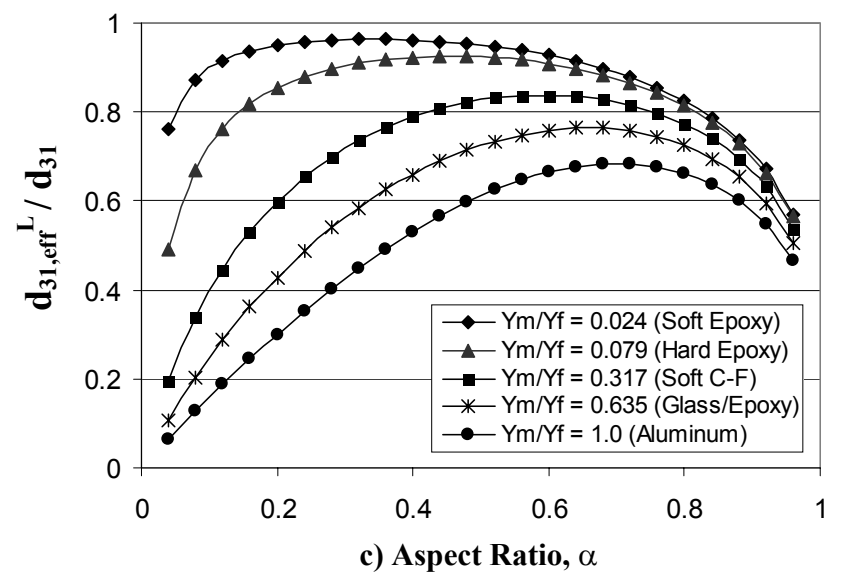

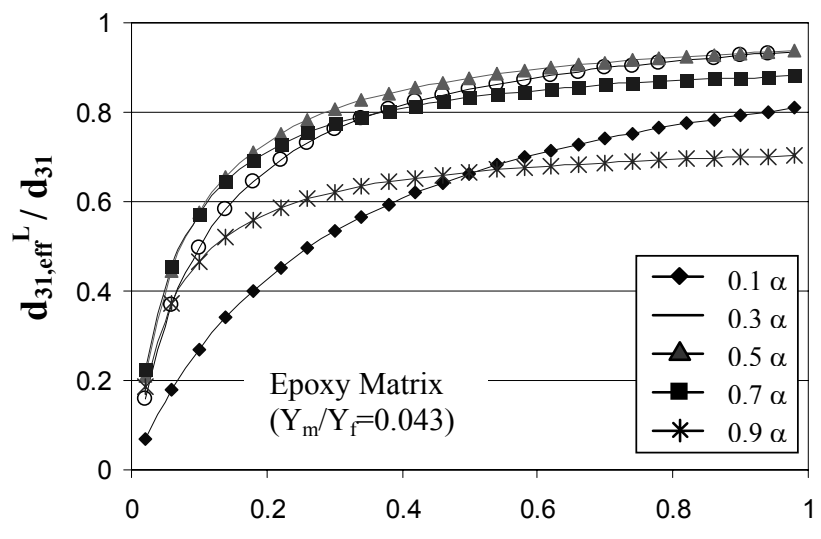

b) Fiber Density, $\Delta_{\mathrm{f}}$

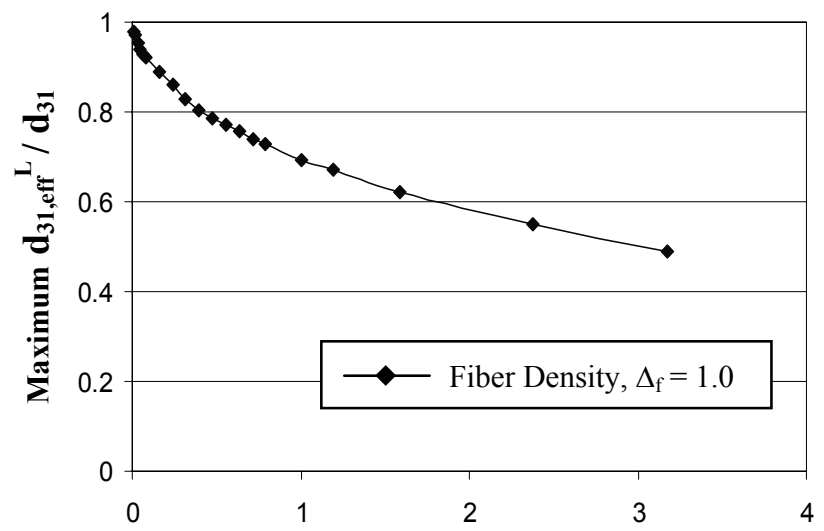

d) Modulus Ratio, $\mathbf{Y}_{\mathbf{m}} / \mathbf{Y}_{\mathbf{f}}$

Figure 4. PZT / Epoxy Effective Lamina $d_{31}$. a) The effective lamina $d_{31}$ normalized by material $d_{31}\left(d_{31}\right.$,eff $\left./ d_{31}\right)$ was plotted as a function of volume fraction for several aspect ratios. b) The normalized effective lamina $d_{31}$ was plotted as a function of fiber density. The largest lamina $\mathrm{d}_{31}$ was $94 \%$ of the material $\mathrm{d}_{31}$, corresponding to $254 \mathrm{pm} / \mathrm{V}$ for PZT-5H, for fiber aspect ratios from approximately 0.3 to 0.5 . c) The normalized effective lamina $\mathrm{d}_{31}$ (calculated at maximum fiber density) was plotted as a function of aspect ratio for several modulus ratios. d) The maximum value of the normalized effective lamina $d_{31}$ was plotted versus the modulus ratio and varied from 0.96 for very soft epoxy to 0.48 for steel.

piezoelectric material composing the individual fiber, plotted as a function of volume fraction (Figure 4a) and fiber density (Figure $4 b$ ). These plots are based on the assumption of typical epoxy for the matrix and PZT-5H for the fiber (Young's modulus ratio $\mathrm{Y}_{\mathrm{m}} / \mathrm{Y}_{\mathrm{f}}=0.043$ ). Figure 4(a) indicates that for a given volume fraction, the greatest effective lamina $d_{31}$ is achieved by the lowest aspect ratio fiber. However, the hollow topology of the fibers places an upper limit on volume fraction achievable (Equation 5), dependent on aspect ratio, resulting in the 'cut-off' of each curve. Thus, while the highest individual fiber strain is achieved with the thinnest walled fibers resulting in less electric field losses, overall, a higher lamina strain may be achieved by a thicker walled fiber because they enable a higher potential fiber volume fraction.

Figure 4(b) presents the effective lamina $d_{31}$ in a slightly more intuitive manner because each value of fiber density corresponds to an equal number and arrangement of fibers within the matrix, regardless of their individual aspect ratio. As expected, the maximum effective lamina $\mathrm{d}_{31}$ occurs at maximum fiber density $(254 \mathrm{pm} / \mathrm{V}-93.9 \%$ of the piezoelectric material $\mathrm{d}_{31}$ ). It is interesting to note, however, that this maximum lamina $d_{31}$ is achieved near the mid-range aspect ratio values of 0.3 and 0.5 . This highlights one of the trade-offs that must be considered when choosing an aspect ratio for active composite applications. The 
Table 1. Optimum Aspect Ratio vs. Matrix Material. As the Young's modulus ratio is increased, the optimum aspect ratio (producing the maximum effective lamina $d_{31}$ increases) while the value of this effective $d_{31}$ decreases.

\begin{tabular}{|l|c|c|c||}
\hline Matrix Material & $\begin{array}{c}\text { Modulus Ratio } \\
\left(\mathbf{Y}_{\mathbf{m}} / \mathbf{Y}_{\mathbf{f}}\right)\end{array}$ & $\begin{array}{c}\text { Optimum } \\
\text { Aspect Ratio }\end{array}$ & $\begin{array}{c}\text { Maximum Effective } \\
\text { Lamina d }_{\mathbf{3 1}} / \mathbf{M a t . ~}_{\mathbf{3 1}}\end{array}$ \\
\hline Soft Epoxy & 0.024 & 0.36 & $\mathbf{9 6 \%}[260 \mathrm{pm} / \mathrm{V}]$ \\
\hline Hard Epoxy & 0.079 & 0.46 & $\mathbf{9 2 \%}[248 \mathrm{pm} / \mathrm{V}]$ \\
\hline Soft C-F Matrix & 0.317 & 0.60 & $\mathbf{8 4 \%}[227 \mathrm{pm} / \mathrm{V}]$ \\
\hline Glass/Epoxy & 0.635 & 0.64 & $\mathbf{7 6 \%}[205 \mathrm{pm} / \mathrm{V}]$ \\
\hline Aluminum & 1.0 & 0.70 & $\mathbf{6 8 \%}[184 \mathrm{pm} / \mathrm{V}]$ \\
\hline Steel & 3.1 & 0.77 & $\mathbf{4 9 \%}[132 \mathrm{pm} / \mathrm{V}]$ \\
\hline
\end{tabular}

thin-walled fiber exhibits the highest effective fiber $\mathrm{d}_{31}$, but cannot effectively activate the composite due to limitations on the achievable volume fraction of these fibers. The thick-walled fiber, although more able to activate the composite because of its higher crosssectional area, has the lowest effective fiber $\mathrm{d}_{31}$ (Equation 2). Thus, the maximum lamina $\mathrm{d}_{31}$ is achieved by balancing the high effective $d_{31}$ of the thin wall fibers with the high volume fraction of the thick wall fibers. Figure 4(c) is a plot of the effective lamina $\mathrm{d}_{31}$ versus aspect ratio for a variety of material modulus ratios $\left(\mathrm{Y}_{\mathrm{m}} / \mathrm{Y}_{\mathrm{f}}\right)$, and Figure 4(d) plots the maximum normalized effective lamina $d_{31}$ (achieved using the optimum aspect ratio) against modulus ratio, with the results summarized in Table 1 . The optimum aspect ratio ranged from 0.36 for the softest matrix to 0.77 for steel, and generally followed an upward trend with matrix modulus. The ratio of the effective lamina $\mathrm{d}_{31}$ to material $\mathrm{d}_{31}$, however, decreased with matrix stiffness, ranging from $96 \%$ for soft epoxy to $48 \%$ for steel (Figure 4d). Essentially, for maximum performance as the stiffness of the matrix is increased, the fiber aspect ratio must also be increased to match the stiffness of the matrix (through increased volume fraction). Unfortunately at the same time, inefficiencies due to the electric field gradient also increase with aspect ratio; thus, these two effects must be balanced to arrive at an optimal aspect ratio.

\section{Embedding Stress Modeling}

The maximum Young's modulus ratio is limited by the embedment stresses that an individual fiber can withstand. These stresses arise from the relative difference in strain between the matrix and the fiber caused by thermal effects during a casting process (thermal expansion coefficient mismatch), or strain induced during curing, as with epoxy. A detailed derivation of these stresses is presented in Cannon and $\mathrm{Brei}^{20}$ and summarized here for completeness. The fiber was modeled as a cylindrical pressure vessel with an internal pressure equal to atmospheric. Using the expressions for radial and circumferential (hoop) stress in the vessel wall, the maximum Von Mises stress occurs at the interior wall, and the only non-zero stresses at this location are hoop and axial (longitudinal) stresses. The hoop stress was derived by recognizing that the contraction of the matrix around the fiber results in an equivalent shrink fit interference. ${ }^{24}$ Assuming the bond between fiber and matrix is ideal, the rule of mixtures was applied to derive the longitudinal stress on the inside wall of the fiber. The longitudinal and hoop stresses, $\sigma_{l}$ and $\sigma_{\theta}$, were combined to yield the non-dimensional Von Mises stress, $\sigma *_{v m}$, at the inner wall of the fiber,

$$
\sigma^{*}{ }_{v m}=\frac{\sigma_{v m}}{Y_{f}\left(\delta_{m}-\delta_{f}\right)}=\frac{\left[\sigma_{\theta}{ }^{2}+\sigma_{l}{ }^{2}-\sigma_{\theta} \sigma_{l}\right]^{1 / 2}}{Y_{f}\left(\delta_{m}-\delta_{f}\right)},
$$

where $\sigma_{l}$ is given by

$$
\frac{\sigma_{l}}{Y_{f}\left(\delta_{m}-\delta_{f}\right)}=\frac{-1}{1+\left(\frac{Y_{f}}{Y_{m}}\right)\left(v_{f}\right)},
$$

and $\sigma_{\theta}$ is given by

$$
\frac{\frac{\sigma_{\theta}}{Y_{f}\left(\delta_{m}-\delta_{f}\right)}=}{\left(\beta^{2}-1\right)\left[\frac{Y_{f}}{Y_{m}}\left(\frac{1+v_{f}}{1-v_{f}}+\mu\right)+\left(\frac{\beta^{2}+1}{\beta^{2}-1}-\mu\right)\right]} .
$$

In these expressions, the quantity $\left(\delta_{m}-\delta_{f}\right)$ is simply the strain differential between the matrix and fiber during curing, and $\beta$ is a non-dimensional intermediate variable equal to $(1-\alpha)^{-1}$. Thus, all three design 


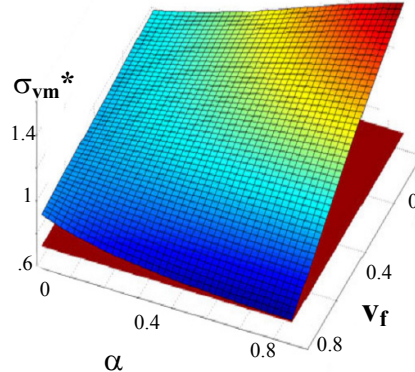

a) Steel

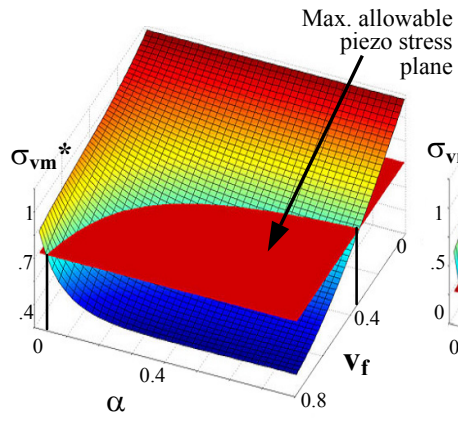

b) Aluminum

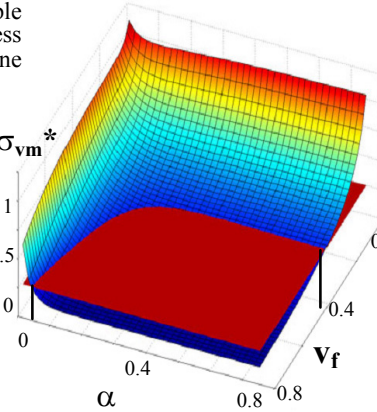

c) Carbon fiber

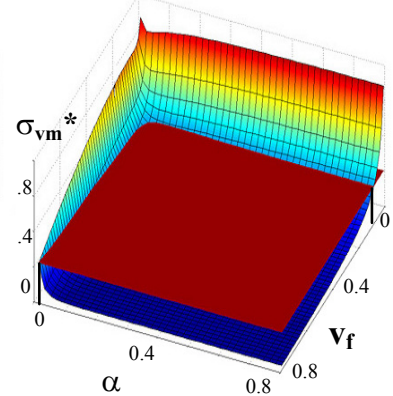

d) Epoxy

Figure 5. Embedding Stresses. The non-dimensional Von Mises stress at the inner wall of a fiber is plotted as a function of fiber aspect ratio $(\alpha)$ and volume fraction, $v_{f}$. The red horizontal plane represents the allowable upper limit for the Von Mises stress during embedment. a) For steel matrices, the embedding process results in stresses above the failure limit for all conditions. b) For aluminum matrices, however, the stresses are below the limit for volume fractions above 0.35 and aspect ratios higher than 0.1. c) For carbon fiber matrices, stresses are below the allowable limits for volume fractions above 0.45 and all aspect ratios higher than 0.35 . d) For epoxy matrices, stresses are below the limits for nearly all aspect ratios and volume fractions.

variables, aspect ratio, volume fraction, and modulus ratio, play an important role in the stresses on a fiber during embedding.

\section{Embedment Stress Analysis}

The non-dimensional Von Mises stress is plotted in Figure 5 as a function of fiber aspect ratio and the volume fraction of the composite for various matrix materials. For the aluminum and steel matrices, the strain differential was taken to be the difference in thermal expansion coefficients multiplied by the temperature drop during cooling of the matrix (solidus temperature minus room temperature). For most metal alloys, this value is approximately one percent. For epoxy and carbon fiber/epoxy matrices, the strain differential used was the cure shrinkage of a typical epoxy, or $2 \%{ }^{25}$ The metals were examined because, unlike traditional active composites, the nature of hollow fibers allows them to be embedded in electrically conductive matrices. The horizontal stress plane shown in red on the graphs denotes the maximum allowable value of the non-dimensional stress (stress values above this plane exceed the maximum compressive stress for typical piezoceramics). A steel matrix (Figure 5a), which is three times stiffer than the fiber, results in stresses above the failure limit of the piezoelectric ceramic regardless of the fiber aspect ratio or volume fraction. It is possible, however, to embed fibers in softer metals, such as aluminum (Figure 5b) that have approximately the same modulus as piezoelectric ceramics, depending on the aspect ratio and volume fraction. For an aspect ratio of 0.8 , a minimum volume fraction of approximately 0.35 is necessary to prevent failure. However, as the volume fraction is increased, the necessary aspect ratio of the fibers drops. For example, for a mid-range volume fraction of 0.45 , fibers with an aspect ratio above 0.3 will survive the embedding process in aluminum. When using extremely high volume fractions $(>0.8)$, an aspect ratio as low as 0.1 is sufficient to prevent failure. For typical carbon fiber matrices (Figure 5c), stresses are below the allowable limits for volume fractions above 0.45 and all aspect ratios higher than 0.35 . Similar to aluminum, the aspect ratio can be as low as 0.09 , provided extremely high volume fractions are used $(>0.8)$. For epoxy matrices much softer than PZT (Figure 5d), stresses are below the limit for all volume fractions and aspect ratios (stress levels appearing above the plane at the edges of the plot are an artifact due to shear lag effects not included in the model). Therefore, although some metals with greater stiffness than PZT $\left(Y_{m} / Y_{f}>1\right)$, such as steel, are not suitable for use with hollow fibers, it is feasible to embed hollow fibers into epoxies, carbon fiber matrices of various hardness, and even metals with Young's modulus on the order of PZT, provided the aspect ratio and volume fraction are sufficiently high.

\section{HOLLOW FIBER FABRICATION AND EVALUATION}

The performance study indicates that the geometric (aspect ratio) and the material (Young's modulus and $d_{31}$ ) properties govern the strain behavior of the AFC and embedment stresses constrain the potential matrix material. Clearly, fabrication method selected for the fibers will have a direct impact on all of these 


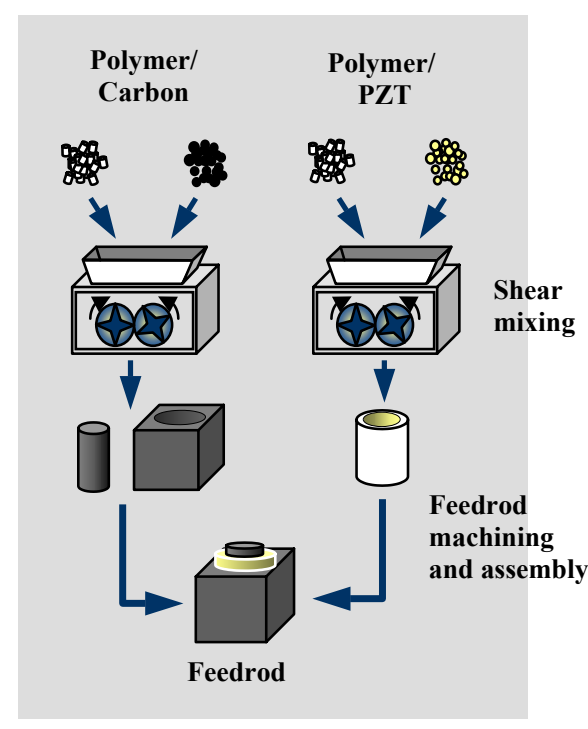

a) Step 1. Feed rod formation

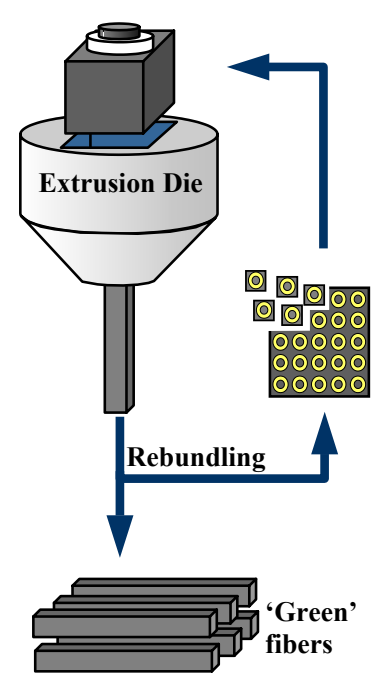

b) Step 2. Extrusion

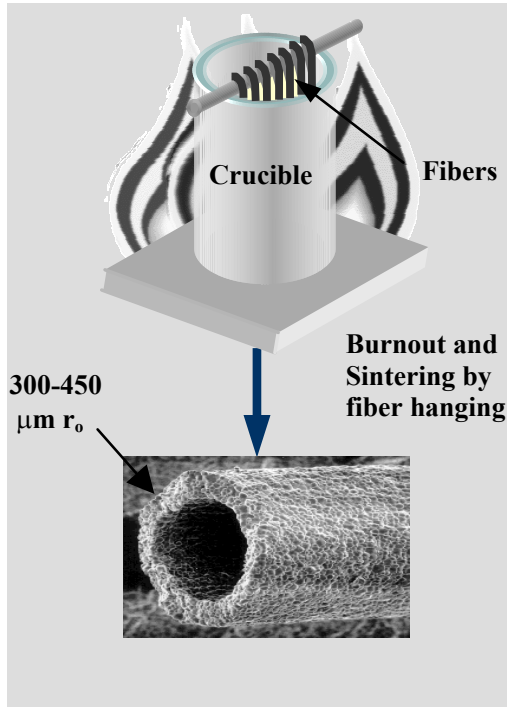

c) Step 3. Burnout/Sintering

Figure 6. MFCX Overview. Piezoelectric and carbon black powders are mixed with thermoplastic polymers to form an initial feedrod. The feedrod is extruded (and re-extruded) until desired fiber size is produced. Polymers and carbon black are removed during burnout to produce the final fiber.

parameters. Unfortunately, the methods available for fabricating these types of fibers, drawing, extrusion, and coextrusion, are relatively new and the variability in the key fiber parameters has not been documented. This section describes an evaluation of fibers fabricated using the Microfabrication by Coextrusion (MFCX) process, chosen because it has been highly successful in producing forms of arbitrary cross-section on a small scale (on the order of grain size) out of a variety of ceramic materials. ${ }^{19}$ Furthermore, the ability to apply this method both efficiently and inexpensively to hollow circular PZT fibers has previously been demonstrated. ${ }^{20}$ Fibers fabricated by this method were evaluated for their geometric properties (ovality, eccentricity, straightness) and material properties (density, porosity, $\mathrm{d}_{31}$ and Young's modulus). A brief overview of the MFCX process is provided; for more detail the reader is referred to earlier research. ${ }^{19,20}$

\section{Microfabrication by Coextrusion (MFCX) Overview}

The MFCX process can be described as a multi-phase, or multi-material extrusion process, as depicted in Figure 6. Carbon black powder and PZT-5H (APC PZT-856) powder were each combined with thermoplastic polymers in a shear mixer (Model PL2100, CW Brabender Instruments, Inc.) at approximately $160^{\circ} \mathrm{C}$ at a speed of $30 \mathrm{rpm}$ until the mixtures were of equal viscosity. Viscosity matching is critical because it allows the two materials to be simultaneously extruded without cross-sectional deformation. Each of the mixtures was hardened by cooling to room temperature, warm-pressed into a solid block of material, and then machined to create a feedrod (Figure 6a). The cross-sectional dimensions of the feedrod were chosen so that the aspect ratio matched the desired fiber aspect ratio. During the extrusion step, the feedrod was forced through a reduction die at approximately $1200 \mathrm{~kg}$ on a Bradley University Research Extruder, reducing its diameter by a factor of 25, but maintaining the aspect ratio of the original feedrod. By re-bundling the extrudate and making multiple extrusion passes (Figure 6b), diameter reductions up to three orders of magnitude are possible. To create the hollow fiber cross-section, the carbon black core and the thermoplastic polymers were removed during the burnout cycle by slowly heating the fibers over 18 hours to a temperature of $600^{\circ} \mathrm{C}$ (HIPAN Series furnace, Micropyretics Heaters International). Finally, the fibers were sintered by heating at a rate of $180^{\circ} \mathrm{C}$ per hour to a two-hour dwell at $1285^{\circ} \mathrm{C}$ to strengthen and densify the ceramic. To prevent fiber warping, a common problem in ceramics processing, it was necessary to burnout and sinter the fibers vertically, hanging under their own weight (Figure 6c). During the post-processing phase of fiber electroding and poling, gaining access to the fiber interior was problematic due to the hollow fiber topology and the extremely small hole in the fiber center. To address this problem, a unique electrode pattern was introduced 
during this step, where the inside electrode was extended around the end of the fiber to an external patch, enabling access to both the inside and outside electrodes from the exterior of the fiber. Silver paint was used to electrode the fibers (DuPont Conductor Composition \#7421), creating a large enough electrode patch so that multiple fibers could be connected through a single electrical bus, as shown in Figure 7. A gap (approximately 2mm) separated the inner and outer electrodes, allowing the fibers to be poled in air without arcing. Each of the fibers was poled by applying an electric field of $1200 \mathrm{~V} / \mathrm{mm}$ at room temperature for approximately 30 minutes. For the evaluation effort, approximately $200 \mathrm{PZT}-5 \mathrm{H}$ fibers of varying outside radius $(300-450 \mu \mathrm{m})$ and aspect ratio $(0.3-0.52)$ were fabricated; examples are shown in Figure 8.

\section{Geometric Property Evaluation}

During the coextrusion process the cross-section of the feedrod can be deformed, which can lead to variations in wall thickness in a single fiber, ultimately resulting in electric field variations. The optimum fabrication process would minimize the cross-sectional deformation. It is also important that the process be repeatable so that there is minimal variation in diameter and wall thickness (and thus electric field) between fibers as well. The nominal diameter measurements made during the cross-sectional analysis were utilized to assess the repeatability of the MFCX process. The largest deviation from the nominal diameter was $4.8 \%$ for the lowest aspect ratio fibers (0.3), whereas the larger aspect ratio fibers $(0.42,0.52)$ had a maximum deviation of $1.8 \%$, much less than the common ceramics processing tolerance of $\pm 5 \%$. To measure the geometric quality of the MFCX fiber fabricated, two cross-sectional properties commonly used in machinery shaft inspection were applied to the hollow fibers: ovality and eccentricity. ${ }^{26}$ Ovality is a measure of the out-of-roundness, or 'lobing' of the cross-section, and is defined as the maximum diametrical deviation from a nominal diameter. Eccentricity, as it applies to hollow fibers, is simply a measure of the distance that the hole

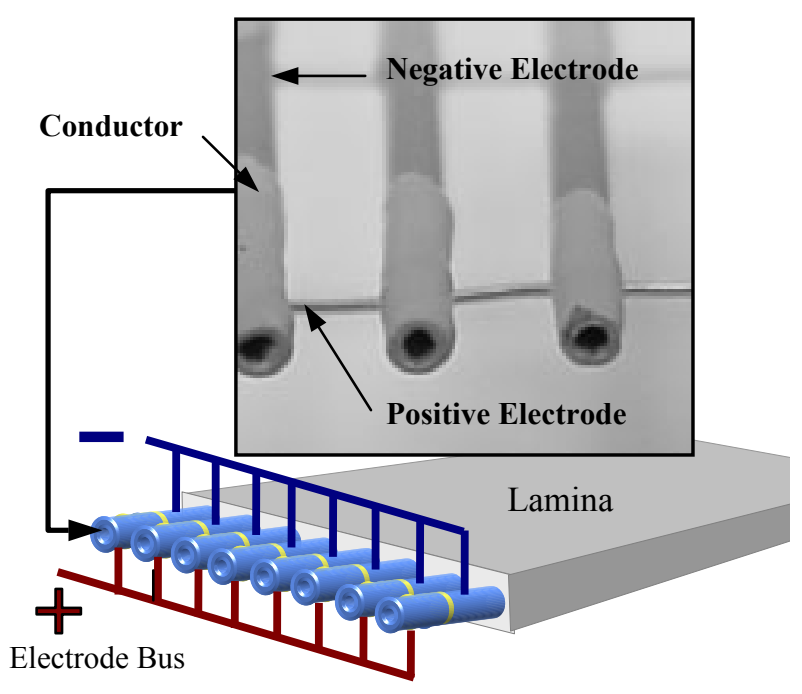

Figure 7. Wrapped electrode pattern. By wrapping the inner electrode to the outside of the fiber, multiple fibers could be connected through a single electrode bus.

is off-center with respect to the outside diameter of the fiber. These two cross-sectional properties are important to the design of a hollow PZT fiber because both ovality and eccentricity cause wall thickness variations, leading directly to electric field variations within the fiber wall. To measure these quantities, the diameter and wall thickness of approximately 40 fibers were measured using calipers at 12 points around the fiber's circumference (Table 2). The average ovality measured resulted in minimal electric field gradients ranging from $1.9 \%$ for the largest aspect ratio evaluated $(0.52)$ to $4.1 \%$ for the smallest aspect ratio $(0.3)$. However, more significant electric field variations arose due to the eccentricity of the fibers, which ranged from $2.1 \%$ to $3.2 \%$. Although these values may appear insignificant, a center hole which is slightly off-center can drastically impact the wall thickness, in this case resulting in field variations as high as $21 \%$ for the 0.3 aspect ratio fibers. For aspect ratios of 0.42 and 0.52 ,

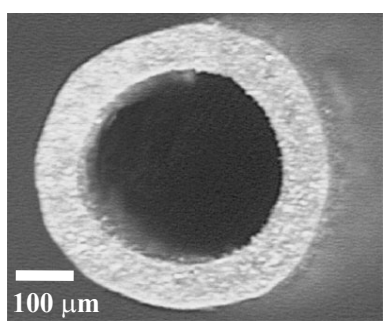

Aspect Ratio $=0.3$

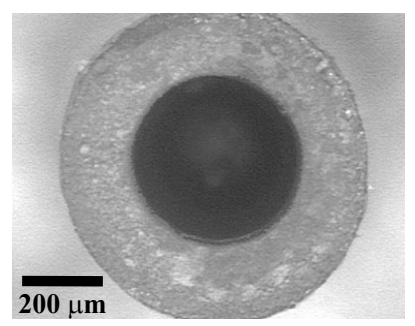

Aspect Ratio $=0.42$

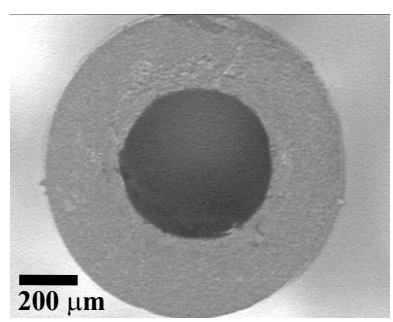

Aspect Ratio $=0.52$

Figure 8. Hollow Fiber Prototype Cross-sections. Each of the hollow PZT fibers was examined for variations in diameter and wall thickness. In each case, the largest deviations occurred in the 0.3 (lowest) aspect ratio fibers. 
Table 2. Hollow Fiber Cross-sectional Analysis. In general, ovality and eccentricity increased as aspect ratio decreased. Ovality ranged from $1.9 \%$ to $4.1 \%$ and eccentricity ranged from $2.1 \%$ to $3.2 \%$.

\begin{tabular}{|l|c|c|c|c|c|c||}
\hline \multirow{2}{*}{} & \multicolumn{2}{|c|}{ Aspect Ratio = 0.3 } & \multicolumn{2}{c|}{ Aspect Ratio= 0.42 } & \multicolumn{2}{c|}{ Aspect Ratio=0.52 } \\
\cline { 2 - 7 } & Ovality (\%) & Eccentricity (\%) & Ovality (\%) & Eccentricity (\%) & Ovality (\%) & Eccentricity (\%) \\
\hline Average & $4.1 \%$ & $3.2 \%$ & $2.1 \%$ & $2.1 \%$ & $1.9 \%$ & $2.1 \%$ \\
\hline Std. Dev. & $2.21 \%$ & $1.34 \%$ & $1.44 \%$ & $0.99 \%$ & $0.40 \%$ & $0.27 \%$ \\
\hline
\end{tabular}

the electric field variation due to eccentricity dropped to $9.9 \%$ and $8.1 \%$. Overall, the largest levels of eccentricity and ovality occurred in fibers with the thinnest wall, indicating that the ability of the fiber to maintain its shape throughout the process diminishes with decreased aspect ratio. When incorporated into an active composite, the electric field variations brought about by eccentricity and ovality will result in field levels both above and below the nominal voltage applied; thus, potential material damage or decreased performance must be taken into account in the active composite design, especially when using fibers with extremely low aspect ratio.

Similar to the cross-sectional property analysis, the straightness of the fibers was determined using two machinery inspection criteria: curvature (commonly used for shaft characterization) and waviness (commonly used for surface characterization). ${ }^{26}$ The curvature of the fiber is essentially the maximum deviation from a nominal centerline, normalized by the length of the fiber. However, because this characterization only measures the single worst point along the length of the fiber, a waviness measurement was also made to capture the 'meandering' nature sometimes found in the fibers. Each of these quantities was measured by enlarging photographs of several fibers and using calipers to measure the deviation of the fiber axis from its nominal centerline at approximately 20 points along the length. Both measurements were normalized by the diameter of the fibers, with the curvature taken to be the maximum deviation and the waviness taken to be the root-mean-square of all measurements taken. Similar to the cross-sectional analysis, the lowest aspect ratio fibers exhibited the highest level of variation along the fiber length. However, even the fibers with the worst measured curvature and waviness $(8.1$ microns $/ \mathrm{mm}$ length and 3.3 microns/mm length, respectively) can be incorporated into lamina less than $50 \%$ thicker than the fiber diameter without exposing the fiber, allowing the fabrication of very thin, high volume fraction composites. The key manufacturing step that enabled the fabrication of these straight fibers was burnout and sintering. During this phase, the basic MFCX process was modified by hanging the fibers vertically versus laying them down, drastically reducing warping and improving their straightness. Furthermore, fibers as long as $75 \mathrm{~mm}$ were fabricated in this manner, on the order of active fibers currently being used ${ }^{2}$, without signs of necking or failure.

\section{Material Property Evaluation}

In addition to the large-scale geometric properties of the fiber, a material analysis was conducted to assess the fiber quality based on porosity, density, $\mathrm{d}_{31}$, and Young's Modulus. The density of the hollow fiber PZT was determined using a standard Archimedes density test and was $97.5 \%$ theoretical density, corresponding to a porosity of $2.5 \%$. This porosity compares quite well to commercially available piezoceramics, which have porosity ranging from $2.6 \%$ to $9 \% .{ }^{27}$ To verify that the high quality of the fiber microstructure would lead to good mechanical properties, the Young's modulus and $d_{31}$ of the fabricated hollow fibers were experimentally determined. The Young's modulus was measured through a simple Instron stress/strain experiment on a solid PZT fiber, with measurements ranging from 54.2 to $61.0 \mathrm{GPa}$, very close to the standard book value of $63 \mathrm{GPa}$ given by the supplier for PZT-5H. To measure the $\mathrm{d}_{31}$ of the ceramic, a small disk approximately $1 \mathrm{~mm}$ thick was cut from the end of a solid PZT feedrod. The disk was post-processed in the same manner as the hollow fibers, using the same burnout and sintering schedules, electrode composition, and poling field $(1200 \mathrm{~V} / \mathrm{mm})$. A strain/electric field experiment was performed on the sample, yielding a measured $\mathrm{d}_{31}$ of $290 \mathrm{pm} / \mathrm{V}$. This value is approximately $7.5 \%$ higher than the $\mathrm{d}_{31}$ value of $270 \mathrm{pm} / \mathrm{V}$ for industry standard PZT-5H, indicating high quality piezoelectric properties.

\section{RELIABILITY INVESTIGATION}

The hollow fiber performance study concluded that maximum lamina strain is achieved using individual fibers with an optimum aspect ratio determined by the choice of matrix material. This optimum aspect ratio 
can range from relatively thick-walled fibers $(0.6$ to 0.7 aspect ratio) for stiff matrix materials (above $50 \mathrm{GPa}$ ) to thin-walled fibers ( 0.3 to 0.4 aspect ratio) for softer epoxy matrices (below $5 \mathrm{GPa}$ ). However, the need to utilize thin-walled hollow fibers will have a negative impact on the strength of the fibers, along with the overall composite reliability. Obviously, when designing an active composite, it is critical to be able to predict the ultimate strength and strain-to-failure of the composite so that loading conditions resulting in composite failure can be avoided. Unfortunately, this data is not available for piezoelectric fibers - solid or hollow. Typically, to fully characterize the ultimate stress and strain-to-failure of fibrous composites under multiple loading conditions, a large battery of standardized tests is required such as $0^{\circ}$ tension, $90^{\circ}$ tension, $0^{\circ}$ compression, $90^{\circ}$ compression, $\pm 45^{\circ}$ tension, three-point flexural tests, shear testing, short beam shear testing, and end-notched flexure, among others. $^{23,26}$ Without knowing the primary failure mechanism, however, this is an overwhelming task.

To initiate the general study of reliability in piezoelectric fibers, an experimental investigation was launched to identify the primary failure mechanism and measure the interfacial shear strength to gain insight into the strain-to-failure and ultimate normal and shear strengths in the transverse and longitudinal direction. Single fiber tests were chosen because they are capable of determining with fewer fiber coupons a) the failure mechanism of the composite near fiber breaks, b) the interfacial shear strength between the matrix and the fiber, and c) the strain-to-failure of an individual fiber. Although these tests cannot predict the exact values of ultimate strength and strain-to-failure in a composite, research has shown that there is a strong qualitative correlation between the interfacial shear strength (or failure mechanism) in a composite and its transverse normal ultimate strength and ultimate shear strength. $^{28,29}$ There are three main types of single fiber tests: single fiber pullout, single fiber indentation, and single fiber fragmentation. Although all three of these methods give the interfacial shear strength of a composite, the fiber pullout test is difficult to conduct on a brittle fiber such as PZT. Thus, the single fiber fragmentation test was conducted to determine the primary failure mechanism, and a simple indentation test was conducted to determine the interfacial shear strength. While interfacial shear strength and failure mechanism can give information about the ultimate strength and strain-to-failure under loading conditions resulting in shear and transverse normal stresses, researchers have found that the correlation between single fiber test results and the longitudinal ultimate strength and strain-to-failure is weak. ${ }^{23,29}$ Therefore, the fragmentation and indentation tests were augmented with a standard $0^{\circ}$ tensile strain-to-failure test that directly determined the composite longitudinal strainto-failure and ultimate strength. ${ }^{26}$

\section{Tensile Strain-to-Failure Testing}

To directly measure the longitudinal strain-to-failure and ultimate strength of the PZT/Epoxy samples, a tensile strain-to-failure test was conducted using a standard Instron tensile test procedure. Each test coupon was mounted and secured between two wedge action tensile grips in an Instron Satec Model 1137 load frame. The cross sectional area and length were input to LabView 5.0 data acquisition software (National Instruments), which monitored the crosshead displacement and the tensile load on the coupon, both output by the Instron. From this data, the strain-tofailure (crosshead displacement / gauge length) and ultimate strength (crosshead load / cross-sectional area) of the sample were calculated.

The strain-to-failure test procedure was applied to four different types of coupons: epoxy blanks containing no fibers, low aspect ratio hollow fibers $(\alpha=0.42)$, high aspect ratio hollow fibers $(\alpha=0.52)$, and solid fibers. The baseline epoxy blanks were tested because the strain-to-failure of the epoxy was not provided by the manufacturer and is dependent on curing parameters such as atmosphere and temperature. Two different aspect ratio hollow fibers were chosen to determine the effect of aspect ratio on the strain-to-failure of the composite. Similarly, the solid fiber coupons were tested to provide a comparison between the hollow fiber design and existing solid fiber active composites. For all of the fibrous coupons, the strain-to-failure was compared to the blank epoxy specimens to determine the overall effect of the embedded fiber on the tensile strain-to-failure of the composite.

Sample Preparation. In all, thirty-two strain-tofailure coupons were fabricated using MFCX- eight for each type of sample. Both the solid and hollow fibers were fabricated with APC-856 (Young's Modulus of 63 $\mathrm{GPa}$ and $\mathrm{a} \mathrm{d}_{31}$ of $270 \mathrm{pm} / \mathrm{V}$ (APC, 1998)) with an outside radius of 450 microns. The coupons, shown in Figure 9, were fabricated using a five-part Delrin ${ }^{\mathrm{TM}}$ mold. A thin layer of Struers' Epofix ${ }^{\mathrm{TM}}$ epoxy $(1.2 \mathrm{GPa}$ Young's Modulus) was poured into the mold and allowed to partially cure until viscous enough to support the weight of a PZT fiber. A single fiber was then placed into the center of the mold, and a second epoxy layer of equal thickness was poured to center the fiber in the coupon. The epoxy was cured for six hours at approximately $40^{\circ} \mathrm{C}$, the temperature at which air bubbles would escape for a nominal epoxy thickness of $4 \mathrm{~mm}$. Once fully cured (approximately 12 hours), the 

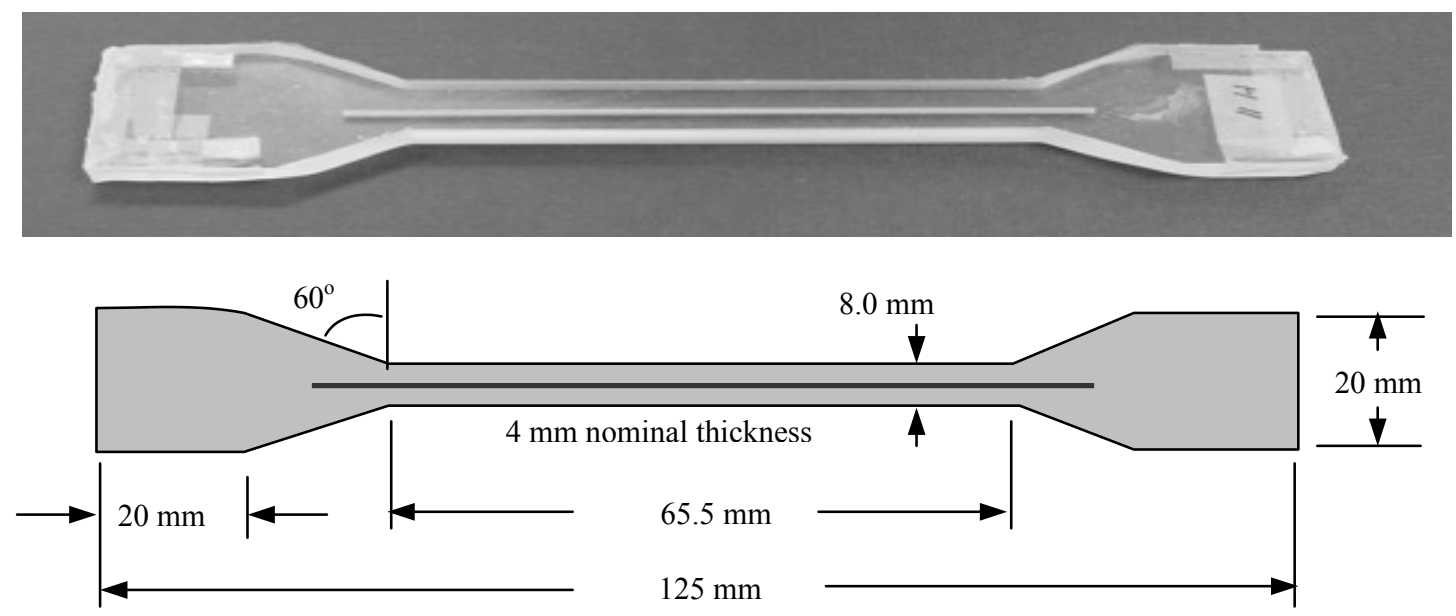

Figure 9. Strain-to-Failure and Single Fiber Fragmentation Test Coupon. Test coupons were fabricated from epoxy and a single PZT fiber. Both hollow and solid test specimens were fabricated. To allow fiber observation during testing, the epoxy was cured at $40^{\circ} \mathrm{C}$ (to remove air bubbles) and the coupons were ground and polished until transparent.

samples were ground and polished, resulting in a transparent single fiber lamina. The resulting coupons measured $125 \mathrm{~mm}$ by $20 \mathrm{~mm}$ with thickness ranging from 3.8 to $4.3 \mathrm{~mm}$.

$\underline{\text { Results. }}$ The averages and standard deviations for the ultimate stress and strain-to-failure of each sample type are given in Table 3. In general, the variance in the data was relatively low for all sample types with the largest variations occurring in the pure epoxy samples $(0.16 \%)$. The measured strain-to-failure of all of the ceramic fiber test specimens compare well to conventional composite types, falling within the range of values for carbon-reinforced epoxy composites (0.6$1.0 \%$ ), and slightly below glass-reinforced composites $(1.4-1.8 \%) .^{30}$ The same is not true, however, for the ultimate strength of the composites, which approach two orders of magnitude below typical glass- and carbon-fiber composites. This was expected. The role of the fibers in a traditional composite are to reinforce the matrix, and the fibers are therefore chosen based on their high stiffness and strength. Active fibers, on the other hand, are designed solely around the fiber's ability to actuate the composite. Thus, the overall strength of the composite will naturally be lower than conventional composites due to this fundamental difference in design philosophy.

What is more interesting is the comparison of ultimate strength and strain-to-failure between the four sample types tested: epoxy blanks, low aspect ratio, high aspect ratio, and solid fiber coupons.

- Fiber Samples vs. Blank Samples. The largest difference in strain-to-failure occurred between the blank coupons and those with embedded fibers. On average, the fiber samples failed at $0.91 \%$ strain, compared to $1.79 \%$ strain for the blank

Table 3. Composite Strain-to-Failure Test Results. The largest difference in strain-to-failure and ultimate strength occurred between the epoxy blank samples and those with embedded fibers, with solid and hollow fiber samples behaving very similarly.

\begin{tabular}{|l|l|c|c|c|c|}
\hline \multicolumn{2}{|c|}{} & \multicolumn{4}{|c|}{ Sample Type } \\
\cline { 3 - 6 } \multicolumn{2}{||c|}{} & Epoxy Blank & Solid Fiber & $\begin{array}{l}\text { 0.52 Aspect } \\
\text { Ratio Fiber }\end{array}$ & $\begin{array}{c}\text { 0.42 Aspect } \\
\text { Ratio Fiber }\end{array}$ \\
\hline $\begin{array}{l}\text { Strain-to- } \\
\text { Failure }\end{array}$ & Average & $1.79 \%$ & $0.92 \%$ & $0.89 \%$ & $0.91 \%$ \\
\cline { 2 - 6 } & Std. Dev. & $0.16 \%$ & $0.10 \%$ & $0.08 \%$ & $0.12 \%$ \\
\hline $\begin{array}{l}\text { Ultimate } \\
\text { Strength }\end{array}$ & Average & $21.6 \mathrm{MPa}$ & $12.5 \mathrm{MPa}$ & $12.0 \mathrm{MPa}$ & $11.9 \mathrm{MPa}$ \\
\cline { 2 - 6 } & Std. Dev. & $1.2 \mathrm{MPa}$ & $1.2 \mathrm{MPa}$ & $0.8 \mathrm{MPa}$ & $0.5 \mathrm{MPa}$ \\
\hline
\end{tabular}


samples, a decrease in strain-to-failure of $51 \%$. Most likely this decrease was due to residual tensile stresses in the matrix due to the curing process, or the cumulative effects of small cracks at fiber fracture locations resulting in stress concentrations. $^{29}$ Furthermore, this reduction in strain-to-failure is similar to conventional composites such as carbon/epoxy and glass/epoxy, where fiber introduction typically lowers composite strain-to-failures by 40 to $60 \%$. $^{29,30}$

- Hollow samples vs. solid samples. On average, the strain-to-failure of the hollow fiber coupons was $3.0 \%$ lower than the solid fiber coupons; thus, the hollow nature of the fiber when compared to solid fibers does not significantly affect the composite's failure in tension due to induced strain. The same, however, is not true for the composite's ultimate strength. The ultimate strength for the solid fiber samples was approximately $12.5 \mathrm{MPa}, 8 \%$ higher than the two hollow fiber sample types, which had strengths of 11.9 and $12.0 \mathrm{MPa}$. This trend was expected because of the increased cross-sectional area (and thus stiffness) of solid fibers. Although $8 \%$ is a relatively low difference in ultimate strength, this difference is expected to grow as the volume fraction of the composite is increased. For very high volume fractions, for example, the difference in ultimate strength will approach the ratio of cross-sectional area between the solid and hollow fibers. In this limit, very low aspect ratio fibers would have only a fraction of the ultimate strength of solid fibers $(<10 \%)$, whereas high aspect ratio fibers would have an ultimate strength nearly equal to that of solid fibers.

- Low aspect ratio vs. high aspect ratio. Comparing the low and high aspect ratio hollow fibers yielded similar results to the comparison to solid fibers. The difference between the strain-tofailure of the two hollow fiber types was less than $2 \%$, indicating that composite strain-to-failure is not significantly affected by the choice of aspect ratio. There was also little difference in the ultimate strength of the two hollow fiber samples (12.0 $\mathrm{MPa}$ for high aspect ratio vs. 11.9 $\mathrm{MPa}$ for low aspect ratio). However, this small difference is due to the low difference between the aspect ratios tested, as well as the low volume fraction of the tested composites. Similar to the comparison between hollow and solid fiber prototypes, the increased ultimate strength of high aspect ratio fibers, a function of the fiber cross-sectional area, is expected to be more apparent at higher volume fractions.
It is interesting to note that even though the introduction of the PZT fibers into the epoxy matrix caused a reduction in the strain-to-failure of the AFC, the level of strain at which the coupon failed is still a factor of nine above the maximum published value of strain-to-failure of the PZT fiber, approximately $0.075 \%$ (EDO). Thus, there are two possibilities for what is occurring at high strain levels: 1) the fiber maintains its bond with the matrix resulting in tensile fiber fracture, or 2) the fiber debonds from the matrix, resulting in fiber pullout. During testing, audible 'clicking' sounds were heard, suggesting that the fiber was fracturing within the matrix. It was these individual fiber fracture points that were of interest in the single fiber fragmentation testing.

\section{Single Fiber Fragmentation Testing - Composite Failure Mechanism}

To experimentally determine the primary failure mechanism of the composite, a single fiber fragmentation test was conducted. The failure mechanism of the composite was identified by observing the photoelastic stress pattern surrounding a fiber fracture. For any single fiber test, exact correlation between failure mechanism and the ultimate strength and strain-to-failure is complex and analytical models are not in place for a general matrix and fiber material. $^{31,32}$ Normally empirical or finite element simulations are used to derive the general relationships, or "trends" between interfacial shear strength and overall composite properties such as ultimate strength and strain-to-failure under shear and transverse normal loading. Because the direct data for piezoceramic fibers was not available in this research, the failure mechanism of hollow fiber and solid fiber PZT composites were compared to the trends found in conventional composites to draw qualitative conclusions about their strength.

Experimental Procedure. Ten single fiber coupons were fabricated in the same manner as the strain-tofailure testing, using PZT fibers of 0.52 aspect ratio. These coupons were mounted in the Instron and tested at a very low rate (approximately 5 microns/sec.). The strain-to-failure test setup was modified by placing a large polarized light behind the sample and a small polarized lens in front of it (Figure 10). As the light passed through the sample, variations in stress levels in the matrix could be detected through the polarized lens as colored bands, or a photoelastic stress pattern, which helped to locate the fiber breaks. ${ }^{33}$ As the strain on the coupon was increased, the location of each fiber break was photographed at approximately 30 -second intervals until the level of strain approached the maximum value of $0.9 \%$ (determined from the composite strain-to- 


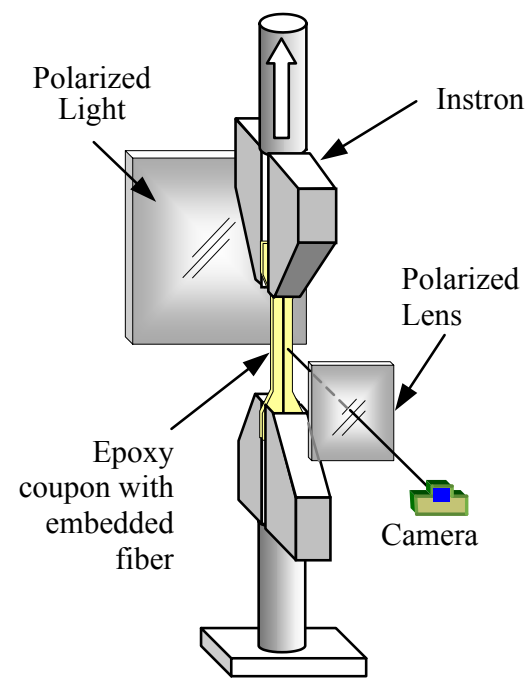

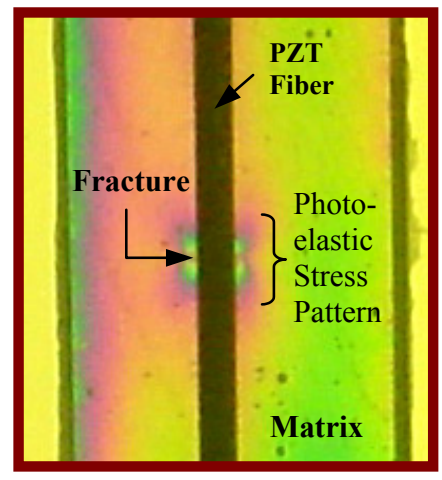

Hollow Fiber

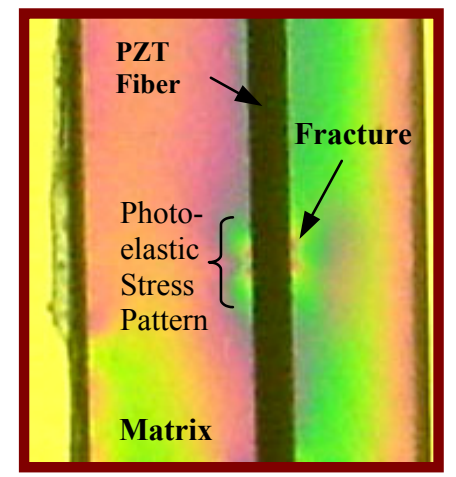

Solid Fiber

Figure 10. Single Fiber Fragmentation Experimental Setup. A single fiber test coupon was observed during tensile testing using transmitted polarized light photography, which allowed the fiber fracture points to be observed directly. For both hollow and solid PZT fibers, the photoelastic stress pattern observed was characteristic of interfacial crack growth.

failure test). At this point, the strain rate was decreased to 2 microns/second to photograph as many instances of fracture as possible before the coupon ultimately failed.

Results. There are three main types of failure mechanisms in fibrous composites ${ }^{29}$ :

- Frictional debonding. Frictional debonding occurs when there is a low level of adhesion between the fiber and the matrix. Under this condition, when the fiber fails, it separates from the matrix and ceases to strain with the matrix. The photoelastic stress pattern typical of this type of failure does not radiate from the fiber because the fiber no longer interacts with the matrix at the point of failure.

- Interfacial crack growth. Interfacial crack growth occurs when there is a moderate level of interfacial adhesion. When the fiber fails under this condition, it does not completely debond from the matrix, and the stress pattern lines appear a small distance from the fiber, surrounding the fracture point, and running parallel to the fiber axis.

- Matrix crack growth. Matrix crack growth occurs when there is an extremely high level of interfacial adhesion. When the fiber fails, it does not separate from the matrix, causing a crack (and thus the photoelastic stress pattern) to extend perpendicular to the fiber, far into the matrix. This results in a very brittle situation, often causing the immediate failure of the entire composite.
For the active composite application, it is important to have a level of interfacial adhesion which results in interfacial crack growth, even more so than in conventional composites. For example, if the bond between the fiber and matrix is too low (resulting in frictional debonding), the fiber cannot transmit shear stresses to the matrix. This would render the entire composite inactive, which is contradictory to the main function of a piezoelectric active composite. On the other hand, a bond that is too strong will result in matrix crack growth, and a composite exhibiting brittle behavior, often failing at low stress levels due to notchsensitive behavior. Therefore, there is an 'optimum level' of adhesion, characterized by interfacial crack growth, resulting in the greatest strain-to-failure of the composite under any loading condition. ${ }^{29}$

The photoelastic stress patterns for the hollow and solid fiber coupons, examples shown in Figure 10, indicates the failure is characteristic of interfacial crack growth. The stress lines are clearly visible surrounding the fracture point, running parallel to the fiber. Therefore, qualitative analysis of the stress patterns in the test coupons show that the level of fiber/matrix adhesion is optimum for the PZT and epoxy that were used for both hollow and solid fiber samples.

\section{Single Fiber Indentation Test - Interfacial Shear Strength}

Since the primary failure mechanism is interfacial crack growth, a single fiber indentation test was conducted to directly measure the value of the interfacial shear 
strength at the fiber/matrix bond. For this test, a test coupon was sectioned into several pieces perpendicular to the fiber length, approximately $0.5 \mathrm{~mm}$ in length. A small steel pin, 600 microns in diameter, was placed directly in series with a force transducer (100 lb max; Sensotec, Columbus, $\mathrm{OH}$ ), and placed against the end of the fiber. A vise was used to slowly increase the force on the fiber until eventually the fiber broke free from the matrix, at which point the maximum force, $P$, was recorded. From this force, the interfacial shear strength, $\tau$, was calculated by simply dividing the force by the area of the fiber in contact with the matrix:

$$
\tau=\frac{P}{\pi d l}
$$

where $l$ and $d$ are the length and diameter of the embedded fiber.

$\underline{\text { Results. }}$ Ten samples were tested, yielding average interfacial shear strength of 59.2 $\mathrm{MPa}$ with a standard deviation of $9.0 \mathrm{MPa}$. While this value is approximately $13 \%$ lower than the optimum interfacial shear strength $(68 \mathrm{MPa})$ reported for carbon fiber/epoxy composites and 50\% higher than values reported for the carbon fiber frictional debonding case, it is well within the range of the interfacial crack growth failure mechanism. $^{29}$ It is important to note that the outcomes obtained for interfacial shear strength and failure mechanism are a function of the exact interaction between the PZT-5H material and the Struer's Epofix epoxy used in this test. Because the empirical results for the single fiber testing available in the literature focus solely on non-active composites, it is not possible to directly predict the numerical values for the ultimate strength of piezoceramic composites under loading conditions. However, conclusions may be drawn for piezoelectric AFC assuming similar correlations between the failure mechanism, interfacial shear strength, and ultimate strength observed in carbon fiber composites. For example, in transverse tension, the ultimate strength of a carbon fiber composite with interfacial crack growth failure mechanism was a factor of 2.1 greater than a similar composite that failed because of frictional debonding. Similarly, for carbon fiber in transverse flexural testing, ultimate strengths of are increased by a factor of 2.8 by changing the failure mechanism from frictional debonding to interfacial crack growth. The influence of the failure mechanism on longitudinal properties such as axial tension and flexure is minimal for carbon fiber, resulting in an increase of only $0.5 \%$ over frictional debonding. ${ }^{30}$ In fact, higher levels of bonding characterized by matrix crack growth resulted in a decrease in longitudinal strain-to-failure, pointing out the importance of avoiding this brittle failure mechanism. ${ }^{29}$ If these same trends hold for piezoelectric fibers, then it can be concluded for the PZT and the epoxy matrix used, the observed failure mechanism and interfacial shear strength result in the best possible properties.

\section{HOLLOW VERSUS SOLID FIBER COMPARISON}

Throughout this work, the design trade-offs introduced by the key design parameters have been heavily focused on. Underlying this analysis, however, is perhaps an even more fundamental design trade-off: the advantages and disadvantages of using hollow fibers versus the current state of the art, solid fibers. To highlight the differences, the effective lamina $d_{31}$ of hollow fiber composites was compared directly to the interdigitated active fiber (solid) composites researched by Bent and Hagood. $^{2}$ This body of work was chosen because it is regarded as one of the largest and most successful applications of long-fiber piezoelectric composites to date, and a substantial amount of modeling and test results are available. To make an accurate comparison, the effective lamina $d_{31}$ of each design was compared at equal fiber volume fraction and material properties. In comparing the performance of hollow fibers to solid fiber active composites, the greatest difference was the maximum potential strain and activation voltage levels. At a volume fraction of $4.5 \%$, the hollow fiber lamina prototype had a measured effective lamina $\mathrm{d}_{31}$ of 153 $\mathrm{pm} / \mathrm{V}$, whereas the solid fiber AFC measured 295 $\mathrm{pm} / \mathrm{V}$, a factor of 1.93 higher than the hollow design. This is not surprising because the solid fiber AFC design exploits the $d_{33}$ mode of the fibers and thus has higher strain potential. In fact, it was expected that this ratio would be approximately 2.25 , the ratio of $\mathrm{d}_{33}$ to $\mathrm{d}_{31}$ in PZT-5H. The lower ratio suggests that a portion of the electric field in a solid fiber AFC is lost in the matrix and does not reach the fiber. For a high volume fraction of $63 \%$, the hollow fiber design has an effective lamina $\mathrm{d}_{31}$ of $92 \%$ of material $\mathrm{d}_{31}$, or 248 $\mathrm{pm} / \mathrm{V}$ (Figure $4 \mathrm{a}, 0.5$ aspect ratio). The measured value for a $63 \%$ volume fraction AFC was $460.2 \mathrm{pm} / \mathrm{V}$, a factor of 1.86 higher than the hollow fiber composite. Therefore, due to the $\mathrm{d}_{33}$ mode of actuation used, interdigitated solid fiber AFCs do have higher effective lamina $\mathrm{d}_{31}$, and thus maximum strain potential, than equivalent hollow fiber composite at both low and high volume fractions.

Although the effective lamina $d_{31}$ of hollow fiber composites is lower than that of solid fiber composites (approximately 50\% less due to the $\mathrm{d}_{31}$ mode of activation), solid fiber AFCs require extreme voltages (kilovolts) because the distance between electrodes must be kept on the order of $1 \mathrm{~mm}$ or larger to allow the 
field to penetrate the matrix and reach the fiber, and to prevent dielectric breakdown of the air between electrodes. In general, fabricating smaller fibers and thinner lamina does not alleviate this fundamental problem. Therefore, to generate the maximum recommended working field of $400 \mathrm{~V} / \mathrm{mm}$, a minimum of 400 volts must be applied. It should be pointed out that solid fiber AFCs can be driven well above the coercive field, as high as $1600 \mathrm{~V} / \mathrm{mm}$, resulting in fiber breakage and re-poling with each actuation cycle. ${ }^{34}$ However, driving the composite at these high field levels results in highly non-linear behavior, and the effect of fiber failure in hollow fiber composites is currently unknown. Therefore, to accurately compare the solid and hollow fibers, only the linear region below the maximum recommended field was considered. In hollow fibers, the electric field is generated across the fiber wall, and in this case the voltage requirement does drop with fiber size. For the lamina prototype tested, $400 \mathrm{~V} / \mathrm{mm}$ was achieved by applying 75 volts. Scaling the hollow fibers tested down to the diameter of the solid AFC fibers $(130 \mu \mathrm{m})$ reduces the voltage required to 10.8 volts, a reduction in voltage of $97 \%$ compared to solid fiber composites. Using lower aspect ratio fibers further reduces the needed voltage. Therefore, the use of hollow fibers does have the potential to drastically reduce the overall voltage needed for composite activation, which is one of the key issues currently impeding the use of the interdigitated AFC design.

One of the obvious drawbacks of the hollow fiber design is that it is potentially weaker than a solid fiber; however, the previous section demonstrated that hollow fibers do not introduce any significant decrease in reliability. Both hollow and solid fibers when embedded in epoxy, exhibit interfacial crack growth indicating a high level of fiber/matrix adhesion necessary for active composites. The interfacial shear strength of the composite samples was $59.2 \mathrm{MPa}$, on the same order as carbon fiber composites. A longitudinal strain-to-failure test was used to provide quantitative information about the strength of the composite in the fiber direction. This testing indicated that the strain-to-failure of the composite was not sensitive to the type of embedded fiber. Both hollow fiber samples failed at approximately the same strain as the solid fiber samples $(0.93 \%$ vs. $0.97 \%)$, as well as at similar strains to carbon fiber composites, which ranged from $0.8 \%$ to $1.6 \%{ }^{29}$ In addition to providing information about composite failure, the single fiber fragmentation test also enabled the strain-to-failure of the individual fiber to be observed. On average, the strain-to-failure of hollow fibers was equal to that of solid fibers, approximately $0.067 \%$, which is more than an order of magnitude below the strain-to-failure of the composite. Therefore, overall the reliability of solid and hollow fibers is comparable. However, the presence of fiber failure within the matrix raises one major difference between the reliability of solid and hollow piezoelectric fiber designs. Solid fiber active composites use an electrode that is external to the matrix, and therefore function regardless of the integrity of the fibers inside the matrix. Hollow fibers, on the other hand, rely on an electrode directly on the surface of the fiber. If this electrode breaks, and loses electrical connectivity, the fiber becomes inactive. Under this failure mode, solid fibers have an advantage over hollow fibers due to the external placement of the electrode. For the hollow design to match the reliability of solid fibers, steps must be taken to ensure that both the inner and outer electrodes remain intact in the event of the piezoelectric material in the fiber failing.

\section{CONCLUSIONS}

It was shown throughout this paper that the three primary design variables play critical roles in the performance, fabrication and reliability of hollow fibers with interesting design tradeoffs arising. Of the three design parameters, aspect ratio had the greatest overall effect, with impact on all areas of hollow fiber design. From a performance standpoint, low aspect ratio fibers have the lowest operating voltage, lowest electric field gradient, and highest effective $\mathrm{d}_{31}$ due to the thin fiber wall. When incorporated into a lamina, however, there exists an optimum aspect ratio, depending on the ratio of matrix to fiber Young moduli, which yields the highest effective lamina $\mathrm{d}_{31}$. This optimum aspect ratio ranges from approximately 0.4 for soft epoxy matrices to 0.7 for stiff matrix materials such as aluminum. When fabricating hollow fibers using the MFCX process, the aspect ratio did not affect the waviness, curviness, or material properties of the fibers. However, cross-sectional properties generally improved (low ovality and eccentricity) as aspect ratio was increased. Naturally, the fiber aspect ratio also had a strong impact on the reliability of hollow fibers. Due to the high volume fractions achievable by high aspect ratio fibers, they have a higher ultimate strength and can be embedded into much stiffer materials than low aspect ratio fibers. This trend in increased ultimate strength continued as the aspect ratio approached the limit of 1.0, equivalent to a solid fiber.

While aspect ratio has the broadest impact, other design parameters still have a strong influence. For example, the Young's modulus ratio governs the choice of feasible materials. When embedding fibers into the matrix, the lowest stresses within the fiber wall occur for low values of the modulus ratio. In fact, through an embedding stress model, it was shown that the modulus 
ratio must be below 1.0 for fiber embedment, even for the highest aspect ratio fibers (including solid fibers) and volume fractions. Thus, only matrix materials softer than piezoceramic may be utilized. The choice of modulus ratio actually determines the fiber aspect ratio that yields this maximum effective $d_{31}$ value that occurs at the lower ratios.

In general, high volume fractions produce the greatest lamina performance or maximum effective lamina $\mathrm{d}_{31}-$ this is simply because the composite consists of more active material. Because the piezoelectric material has to be stiffer than the matrix $\left(\mathrm{Y}_{\mathrm{m}} / \mathrm{Y}_{\mathrm{f}}<1\right)$ to survive embedment, high volume fractions are required to achieve high ultimate strength. Piezoelectric materials are brittle; thus, composites that are matrix dominated (low volume fraction) tend to have the highest strain-tofailure values.

It is clear from this summary that there is no single value of aspect ratio, volume fraction, or modulus ratio, that is optimal in all configurations; thus, design tradeoffs will always be present when designing a hollow fiber active composite. For example, the choice of fiber and matrix material will dictate a minimum aspect ratio based on the embedding stress model, which must be carefully chosen to achieve the maximum lamina $d_{31}$ and avoid high electric field gradients and lower the operating voltages. Conversely, for low-voltage composites a low aspect ratio must be used which will decrease the geometric quality of the fibers, and severely limit the choice of matrix materials due to reliability issues. Therefore, due to the broad impact of the design parameters introduced in this paper, it is important to consider performance, fabrication, and reliability issues simultaneously in the design of hollow piezoelectric fiber active composites.

\section{ACKNOWLEDGEMENTS}

The authors would like to acknowledge the Active Materials Laboratory at the University of Michigan for assistance in fabricating the fibers, the Air Force Palace Knight program for their financial and personal support, and the Naval Research Laboratory for funding portions of this research.

\section{REFERENCES}

1. Li, L. and Sottos, N.R., 1994, "Consideration of electro-mechanical coupling in the prediction of 13 piezocomposite properties", Proceedings of the 1994 International Mechanical Engineering Congress, AMD, Vol. 193, p 23-32.

2. Bent, A.A., Hagood, N.W., and Rodgers, John P., 1995, "Anisotropic actuation with piezoelectric fiber composites", Journal of Intelligent Material Systems and Structures, Vol. 6, No. 3, May 1995, p 338-349.

3. Maclean, B.J. and Jacobsen, S.C., 1995-96, "Active Fibers for Development of Adaptive Structures", ARPA Actuator Issues Workshop.

4. Fernandez, J.F., Dogan, A., Zhang, Q.M., Tressler,J.F., Newnham, R.E., 1995, "Hollow piezoelectric composites", Sensors and Actuators, A: Physical, Vol. 51 No. 2-3, p 183-192.

5. Zhang, Q., Wang, H., Cross, L.E., 1993, "Piezoelectric tubes and tubular composites for actuator and sensor applications", Journal of Materials Science, Vol. 28, No. 14, p 3962-3968.

6. Krishna-Murty, A.V., Anjanappa, M. A., and Wu, Y., 1996, "Vibration control of magnetostrictive composite beams", Proceedings of SPIE - The International Society of Optical Engineering, Vol. 2717, p 482-491.

7. Sottos, N.R., Kline, G.E., Qidwai, M.A., and Lagoudas, D.C., 1996 "Analysis of phase transformation fronts in SMA composites", Proceedings of SPIE - The International Society for Optical Engineering, Vol. 2715, p 427-438.

8. Guigou, C. and Fuller, C.R., 1997, "Foam-PVDF smart skin for aircraft interior sound control", Proceedings of SPIE - The International Society for Optical Engineering, Vol. 3044, p 68-78.

9. Herold-Schmidt, U., Schaefer, W., Zaglauer, H.W., 1996, "Piezoceramics/CFRP composites for active vibration control and shape control of aerospace structures", Proceedings of SPIE - The International Society for Optical Engineering, Vol. 2779, p 718-723.

10. Rodgers, J.P., Hagood, N.W., and Weems, D.B., 1997, "Design and manufacture of an integral twist-actuated rotor blade", $38^{\text {th }}$ AIAA/ ASME/ASCE/AHS/ASC Structures, Structural Dynamics, and Materials Conference, AIAA Paper No. 97-1264.

11. Thomas, M.M. and Trottier, C. M., 1995, "Industrial fabrication of smart structures for vibration control", Proceedings of the 1995 ASME International Mechanical Engineering Congress \& Exposition, No. 95-WA/NCA-1, New York.

12. Wilkie, W.K., Bryant, R. G., High, J. W. Fox, R. L., Hellbaum, R. F., Jalink, A. Jr., Little, B. D., and Mirick, P. H., 2000, "Low-cost piezocomposite actuator for structural control applications", Proceedings of SPIE - The International Society for Optical Engineering Vol. 399, Bellingham, WA, USA. p 323-334.

13. Safari, A., Janas, V., and Panda, R., 1996, "Fabrication of fine-scale 1-3 $\mathrm{Pb}(\mathrm{Zrx}, \mathrm{Ti1}-$ x)O3/ceramic/polymer composites using a modified lost mold method", Proceedings of 
SPIE - The International Society for Optical Engineering, Vol. 2721, p 251-262.

14. Bowen, L.J., Gentilman, R.L., Pham, H.T., Fiore, D.F., French, K.W., 1993, "Injection molded finescale piezoelectric composite transducers", Proceedings of the IEEE Ultrasonics Symposium, Vol. 1, No. 93CH3301-9, p 499-503.

15. Lubitz, K., Wolff, A., and Preu, 1993, "Microstructuring Technology", Proceedings of the IEEE Ultrasonics Symposium, Vol. 1, No. 93CH3301-9, p 515-524.

16. Klicker, K.A., Biggers, J.V., and Newnham, R.E., 1981, "Composites of PZT and epoxy for hydrostatic transducer applications", Journal of The American Ceramic Society, Vol. 64, No. 1, p 5-9.

17. French, J.D., Weitz, G.E., Luke, J.E., Cass, R.B., Jadidian, B., Bhargava, P., and Safari, A., 1997, "Production of continuous piezoelectric ceramic fibers for smart materials and active control devices", Proceedings of SPIE - The International Society for Optical Engineering, Vol. 3044, p 406412.

18. Strock, H.B., Pascucci, M.R., Parish, M.V., Bent, A.A., and Shrout, T.R., 1999, "Active PZT fibers, a commercial production process", Proceedings of SPIE - The International Society for Optical Engineering, Vol. 3675, p 22-31.

19. Crumm, A.T. and Halloran, J.W., 1998, "Microfabrication of Multicomponent Ceramics", Journal of The American Ceramic Society, Vol. 81, No. 4, p 1053-57.

20. Cannon, B.J. and Brei, D., 2001, "Feasibility study of microfabrication by coextrusion (MFCX) hollow fibers for active composites", Journal of Intelligent Material Systems and Structures, Vol. 11 n 9, p 659-670.

21. Cannon, B.J., 2001, "Piezoceramic hollow fiber active composites", Ph.D. Thesis, The University of Michigan.

22. Halliday, D. and Resnick, R., 1988, Fundamentals of Physics, John Wiley \& Sons, Inc., New York.
23. Hyer, M.W., 1998, Stress Analysis of FiberReinforced Composite Materials, McGraw-Hill Companies, New York.

24. Shigley and Mischke, 1989, Mechanical Engineering Design, McGraw Hill, Inc., New York.

25. Mallick, P.K., 1993, Fiber-reinforced Composites: Materials, Manufacturing, and Design, M. Dekker, New York.

26. ASM, International, 1998, "Engineered Materials Handbook: Composites”, Vol.1, ASM International, Metals Park, $\mathrm{OH}$.

27. Crumm, A.T., 2000, "MicroFabarication by CoeXtrusion", Ph.D. Thesis, The University of Michigan.

28. Deng, S., and Ye, L., 1999, "Influence of fibermatrix adhesion on mechanical properties of graphite/epoxy composites: I. Tensile, flexure, and fatigue properties", Journal of Reinforced Plastics and Composites, Vol. 18, No. 11, p 1021-1040.

29. Drzal, L.T. and Madhukar, M., 1993, "Fibre-matrix adhesion and its relationship to composite mechanical properties", Journal of Materials Science, Vol. 28, p 569-610.

30. Hertzberg, R.W., 1996, Deformation and Fracture Mechanics of Engineering Materials, John Wiley and Sons, Inc., New York.

31. Curtin, W.A. and Takeda, N., 1998, "Tensile strength of fiber-reinforced composites: II. Application to polymer matrix composites", Journal of Composite Materials, Vol. 32, No. 22, p 2060-2081.

32. Tripathi D., and Jones, F.R., 1998, "Single fibre fragmentation test for assessing adhesion in fibre reinforced composites", Journal of Materials Science, Vol. 33, No. 1, p1-16.

33. Durelli, A.J., 1958, Introduction to the Theoretical and Experimental Analysis of Stress and Strain, McGraw-Hill Companies, New York.

34. Hagood, N.W. and Pizzochero, A., 1997, "Residual Stiffness and Actuation Properties of Piezoelectric Composites: Theory and Experiment", Journal of Intelligent Material Systems and Structures, Vol. 8, p 724-737. 